of different materials with varying twist angles. From an applied perspective, charge separation is a critical first step in converting optical excitation into a charge that can be read out in a photodetector or lightharvesting device.

Steven T. Cundiff

Department of Physics, University of Michigan, Ann
Arbor, MI, USA.

e-mail: cundiff@umich.edu

Published online: 19 June 2019

https://doi.org/10.1038/s41563-019-0410-8

\section{References}

1. Geim, A. K. \& Novoselov, K. S. Nat. Mater. 6, 183-191 (2007).

2. Mak, K. F., Lee, C., Hone, J., Shan, J. \& Heinz, T. F. Phys. Rev. Lett. 105, 136805 (2010).
3. Splendiani, A. et al. Nano Lett. 10, 1271-1275 (2010).

4. Merkl, P. et al. Nat. Mater. https://doi.org/10.1038/s41563-0190337-0 (2019).

5. Qiu, D. Y., da Jornada, F. H. \& Louie, S. G. Phys. Rev. Lett. 111 216805 (2013).

6. Tran, K. et al. Nature 567, 71-75 (2019).

7. Seyler, K. L. et al. Nature 567, 66-70 (2019).

8. Jin, C. et al. Nature 567, 76-80 (2019).

9. Alexeev, E. M. et al. Nature 567, 81-86 (2019).

10. Huber, R. et al. Nature 414, 286-289 (2001).

\title{
New dating agency for artists
}

A $s$ the arguments over the painting Salvator Mundi demonstrate - is it the work of Leonardo da Vinci himself? - there is a lot riding on the authentication of art. The painting sold for a recordbreaking US\$450 million on the strength of its attribution to Leonardo, but some say it was made only by his studio, and it has now been excluded from a Leonardo exhibition in the Louvre because of its uncertain status.

Verifying authenticity is sometimes no easier for outright fakes. One of the most successful art fakers of all time, the Dutch painter Han van Meegeren, went to great lengths to disguise the deception, for example by scraping old canvases clean so that they looked suitably aged. Van Meegeren copied the styles of Dutch old masters such as Frans Hals and Jan Vermeer so skilfully that some critics hail his work in its own right, and he became a national hero when it emerged after World War II that he had sold a fake to Hermann Göring during the German occupation of the Netherlands.

Spotting faked paintings usually involves a close inspection of the materials. Sometimes they come to light because of the anachronistic use of pigments: a 'modern' pigment such as chrome yellow could not possibly feature in a genuine Rembrandt. But the canny forger will use periodappropriate paints. Another option is to use radiocarbon dating, but this has traditionally involved destructive testing of a significant amount of material - perhaps a few grams. Those might be taken from the frame or a hidden part of the canvas - but this would be of no avail against a smart practitioner like van Meegeren.

A more exacting test would carry out dating on the paints themselves, looking at the organic components in individual paint layers - in particular the liquid binder, which until the advent of modern acrylic resins was typically a drying oil such as linseed oil, perhaps mixed with natural resins. This level of inspection has not previously been possible, though, because the tests required too much material. However, recent developments in accelerator mass spectrometry (AMS) radiocarbon dating, such as the 'gas ion source' method, have reduced the necessary sample size down to mere micrograms.

This has now enabled Hendriks et al. to identify a modern faked painting by radiocarbon microanalysis of the materials in the paint ${ }^{1}$. Their sample was purposely chosen to be a known forgery: made by the American artist Robert Trotter, who was convicted in 1990 of producing and selling faked American folk art. His Village Scene with Horse and Honn \& Company Factory, signed ' 1866 ' by the 'artist' Sarah Honn, isn't a very sophisticated deception conventional spectroscopic pigment analyses have already revealed telltale anachronisms, such as the total absence of lead white 2 .

But Trotter did use an old canvas, and radiocarbon dating of that is inconclusive, spanning from the late seventeenth century to the

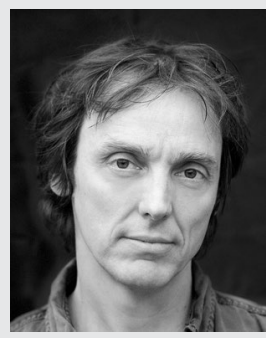

Philip Ball

mid-twentieth century. Dating of a tiny amount of the binder (yielding just $19 \mu \mathrm{g}$ of carbon) has, however, proved more exacting: the oil appears to have come from seeds harvested either in 1958-1961 or 1983-1989. (The double date range comes from the confounding influence of nuclear-bomb radiocarbon in the 1950s and 1960s.) If we didn't know already that this was a fake, we would now.

Trotter, incidentally, is still painting in a faux nineteenth-century style after leaving prison - but openly so, selling to buyers of modern folk art. Making a living as an artist was, it seems, all he had really wanted.

Published online: 19 June 2019 https://doi.org/10.1038/s41563-019-0417-1

References

1. Hendriks, L. et al. Proc. Natl Acad. Sci. USA https://doi. org/10.1073/pnas.1901540116 (2019).

2. Smith, G. D., Hamm, J. F., Kushel, D. A. \&

Rogge, C. E. in Collaborative Endeavors in the Chemical Analysis of Art and Cultural Heritage Materials (eds Lang, P. L. \& Armitage, R. A.) 1-21 (American Chemical Society, 2012). 